\title{
Partial compression strength of sugi (Japanese cedar, Cryptomeria japonica) wood near the pith perpendicular to the grain
}

\author{
Yoshio Kijidani ${ }^{*}$, Hideki Morita ${ }^{2}$, Shiro Aratake ${ }^{2}$, Taku Tsuyama ${ }^{1}$ and Takanori Arima ${ }^{2}$
}

\begin{abstract}
It was reported that sugi (Japanese cedar, Cryptomeria japonica) boards with pith had a greater partial compression strength perpendicular to the grain $\left(\sigma_{\mathrm{e}}\right)$ than sugi boards without pith. However, the reason for the superior strength of sugi boards with pith remains unclear. In this study, as the first step to elucidate the reason, we report the effects of loading direction (tangential and radial), density, microfibril angle (MFA) of earlywood and latewood tracheids, latewood tracheid length and cross-sectional parameters of earlywood tracheids (CE) on $\sigma_{\mathrm{e}}$ in sugi wood. There was no significant effect of loading direction on $\sigma_{\mathrm{e}^{\prime}}$ and the specimens with pith had significantly larger $\sigma_{\mathrm{e}}$ values than the specimens without pith. A larger density, larger MFA, and smaller cross-sectional dimensions with a square shape in earlywood tracheids significantly increased $\sigma_{e}$ in the radial loading direction. By multiple linear regression, it was recognized that density and MFA was the effective parameters, and MFA had a larger effect than did density in the predictor equation for $\sigma_{e}$. This is the first study that reported the positive effects of MFA on $\sigma_{\mathrm{e}}$ in sugi wood.
\end{abstract}

Keywords: Japanese cedar, Juvenile wood, Partial compression strength perpendicular to grain, Microfibril angle

\section{Introduction}

Softwood is one of the most important renewable resources in the world. It is mainly used in the structural components of wooden structures. One major type of wood variation is the variation within a tree caused by the presence of both juvenile and mature wood [1]. Juvenile wood usually has poor strength and is not stable for use in solid wood products [1]. A large microfibril angle (MFA) is often found in juvenile wood [2]. In some species, the large MFA is so prevalent in the juvenile wood zone that, for the purpose of using the wood for boards, the wood quality is very poor [1]. Sugi (Japanese cedar, Cryptomeria japonica) is one of the most important afforestation tree species in Japan. There are enough fully grown trees on sugi plantations. Japanese wood companies do not purchase sugi boards with pith because they have a larger percentage of juvenile wood [3]. Sugi

\footnotetext{
*Correspondence: kijiyo@cc.miyazaki-u.ac.jp

${ }^{1}$ Division of Forest and Environmental Science, Faculty of Agriculture,

University of Miyazaki, Miyazaki 889-2192, Japan

Full list of author information is available at the end of the article
}

boards with large percentage of juvenile wood did not have enough stiffness for laminated lumber. To promote the efficient use of sugi wood, it is important to understand the characteristics of domestic juvenile wood and to propose the optimal applications for utilizing these characteristics.

Sugi has the unique characteristic of radial variation of the density in the stem; the density of sugi is large at the tree center [4]. Morita and Aratake [3] focused on the large density of juvenile wood and used laminated sugi boards with pith to build a prototype bed sill using the conventional Japanese construction method. They expected the prototype bed sill to have a superior partial compression strength perpendicular to the grain $\left(\sigma_{\mathrm{e}}\right)$ and to exhibit durability because of the large density and large heartwood percentage of sugi boards with pith. As they expected, the laminated sugi boards with pith had a $\sigma_{\mathrm{e}}$ superior to those of both laminated sugi boards without pith and sugi boxed-heart square timbers [3]. The density had a positive effect on $\sigma_{\mathrm{e}}$ in sugi boards both with and without pith; however, the linear regression equations of these two types of boards differed. Although the 
density of both types was the same, the $\sigma_{\mathrm{e}}$ of sugi boards with pith was larger than that of sugi boards without pith [3]. Therefore, factors other than density will contribute to the superior $\sigma_{\mathrm{e}}$ of sugi boards with pith. To ensure the reliable use of sugi wood, we should examine the factors affecting the $\sigma_{\mathrm{e}}$ of sugi boards with pith more precisely.

In five coniferous tree species, the $\sigma_{\mathrm{e}}$ of timber with loading in the tangential direction was larger than that with loading in the radial direction except in the case of radiate pine (Pinus radiata) [5]. In a previous study [3], sugi boards with pith and without pith used in laminated lumber (prototype bed sill) were loaded in the tangential direction except near the pith and radial direction respectively, because these boards were edge-grain boards and flat-grain boards respectively. Therefore, the difference in the loading direction may affect the $\sigma_{\mathrm{e}}$ of sugi boards with or without pith.

The deformation of coniferous woods as cellular materials was investigated under radial and tangential compression. Ando and Onda [6] reported that the first fractured cells had a tendency to have the smallest percentage of cell wall within an annual ring of coniferous wood, and the cells suffered shearing deformation in the radial direction until the occurrence of the first fracture. They also suggested that the abrupt first break can be mainly attributed to the buckling of radial cell walls, based on the mechanism of deformation of coniferous woods as cellular materials [7]. Watanabe et al. [8] reported that the calculated Young's moduli using cell models significantly differed among coniferous species depending on the cell model shape when compared at the same density. According to these studies, cross-sectional parameters of earlywood tracheids (CE) might contribute to the radial variation of $\sigma_{\mathrm{e}}$ in sugi boards.

It was reported that a smaller MFA in the $S_{2}$ layer of a tracheid increased the mechanical properties of plantation trees parallel to the grain [9-15]. In terms of the mechanical properties parallel to the grain, specimens with an MFA close to $0^{\circ}$ have superior mechanical properties because the microfibrils in the $S_{2}$ layer, the strongest components in the cell wall, are arranged parallel to the direction of loading and resist the stress efficiently. On the other hand, Sobue and Asano reported that a larger MFA increased the shear modulus of rigidity, although a larger MFA decreased the longitudinal Young's modulus [16]. However, there are few studies of the effects of MFA on $\sigma_{\mathrm{e}}$ of sugi wood.

In the current study, as the first step to elucidate the reason for the superior $\sigma_{\mathrm{e}}$, we examined the effects of the possible factors on $\sigma_{\mathrm{e}}$ of sugi samples. Based on the previous studies described above, we focused on the loading direction, density, MFA, latewood tracheid length and $\mathrm{CE}$ as the possible factors affecting the variation of $\sigma_{\mathrm{e}}$ of sugi wood. The objectives of the current study were to examine: (1) the effects of the loading direction (tangential versus radial loading) on $\sigma_{e}$; and (2) the effects of density, MFA, latewood tracheid length and CE on $\sigma_{\mathrm{e}}$ with loading in the radial direction in sugi woods. This study contributes to understanding of the radial variations of $\sigma_{\mathrm{e}}$ of sugi wood.

\section{Materials and methods \\ Sample trees and specimens}

To meet objective (1), three sugi trees (unknown genetic background, 46-year-old or 49-year-old) grown in stands for timber production established in the experimental forest of Miyazaki University (initial density: 3000 trees/ ha) were used as sample trees in the current study. Several thinnings had been carried out in these stands. The stem stiffness and average density of sample boards at breast height of three sample trees were $9.1 \mathrm{GPa}$ and $0.45 \mathrm{~g} / \mathrm{cm}^{3}, 8.6 \mathrm{GPa}$ and $0.41 \mathrm{~g} / \mathrm{cm}^{3}$ and $7.0 \mathrm{GPa}$ and $0.37 \mathrm{~g} / \mathrm{cm}^{3}$, respectively. As shown in Experiment $\mathrm{I}$ in Fig. 1, two boards with pith were cut from around the breast height position of the sample trees and used for loading in the tangential and radial direction, respectively. Thirty air-dried specimens ( 3 trees $\times 2$ boards $\times 5$ radial positions) were prepared for partial compression tests perpendicular to the grain (Experiment I in Fig. 1, Table 1). The dimensions of the specimens were $4 \mathrm{~cm}$ $(T) \times 4 \mathrm{~cm}(R) \times 30 \mathrm{~cm}(L)$.

To meet objective (2), as shown at Experiment II in Fig. 1, one board with pith was obtained at each of three different height positions $(1.5 \mathrm{~m}, 3 \mathrm{~m}$, and $5 \mathrm{~m}$ above ground) from the logs of seven sugi cultivars used in the previous study [14]. Specimens were obtained from sugi boards with pith for the measurement of anatomical characteristics (MFA, latewood tracheid length and $\mathrm{CE}$ ) and for tests of partial compression perpendicular to the grain. In the previous study, we reported the radial and longitudinal variation of the density and MFA in 17 sugi cultivars [12]. We selected seven cultivars with different density and MFA values from among 17 sugi cultivars based on the results of the previous study. A total of 162 air-dried specimens (7 cultivars $\times 2-3$ height positions $\times 6-12$ radial positions) were prepared for tests of partial compression perpendicular to the grain. The dimensions of the specimens were $2 \mathrm{~cm}(T) \times 2 \mathrm{~cm}$ $(R) \times 6 \mathrm{~cm}(L)$. Density, MFA, and latewood tracheid length vary with the ring number from the pith $[4,12]$. To obtain precise data on the variation of $\sigma_{\mathrm{e}}$ with the ring number from the pith, specimens with small dimensions were prepared to meet objective (2). The average moisture content of all specimens was $10.5 \%$. 
Three sugi trees (unknown genetic background) Two boards with pith from breast height position

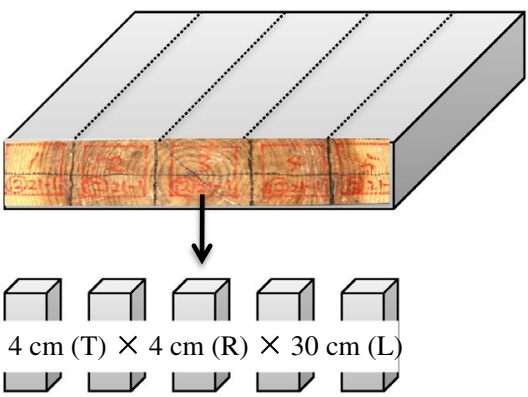

3 trees $\times 2$ boards $\times 5$ radial positions $=30$ specimens

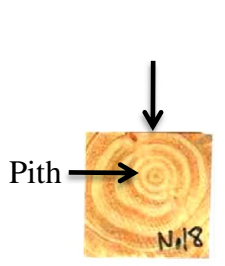

Load
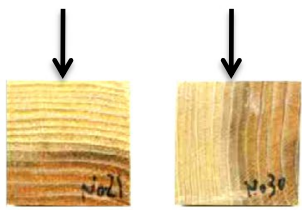

Experiment I
Seven trees (7 cultivars from obi-sugi cultivar group) One board from three height positions (1.5 m, $3 \mathrm{~m}$ and $5 \mathrm{~m}$ above ground)

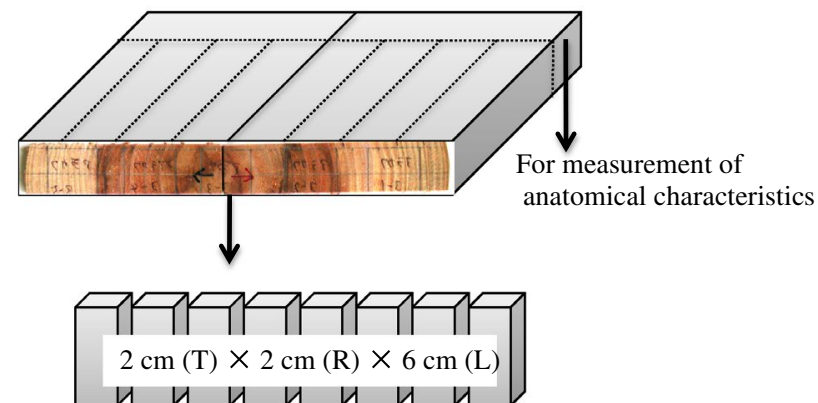

7 trees $\times \quad 2-3$ height positios $\times 6-12$ radial positions $=162$ specimens

Load

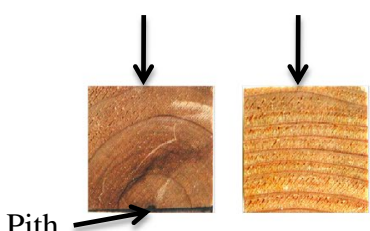

Experiment II

Fig. 1 Scheme of specimens and direction of loading

Table 1 Partial compressive strength perpendicular to the grain of specimens with/without pith

\begin{tabular}{lllllll}
\hline Type of specimen & Loading direction & $\boldsymbol{n}$ & Density $\left(\mathbf{g} / \mathbf{c m}^{\mathbf{3}}\right)$ & $\boldsymbol{\sigma}_{\mathbf{e p}}(\mathbf{M P a})$ & $\boldsymbol{\sigma}_{\mathbf{e} 5 \%}(\mathbf{M P a})$ & $\boldsymbol{\sigma}_{\mathbf{e} 19 \%}(\mathbf{M P a})$ \\
\hline Specimen without pith & Radial & 12 & $0.39(0.04)^{\mathrm{b}}$ & $3.75(0.87)^{\mathrm{a}}$ & $6.27(0.74)^{\mathrm{b}}$ & $9.64(0.94)^{\mathrm{b}}$ \\
& Tangential & 12 & $0.39(0.04)^{\mathrm{b}}$ & $4.92(1.02)^{\mathrm{b}}$ & $6.76(0.89)^{\mathrm{b}}$ & $9.91(1.57)^{\mathrm{b}}$ \\
Specimen with pith & & 6 & $0.49(0.04)^{\mathrm{a}}$ & $5.52(0.98)^{\mathrm{b}}$ & $9.22(1.26)^{\mathrm{a}}$ & $14.72(1.18)^{\mathrm{a}}$ \\
\hline
\end{tabular}

The values represent the averages, and the values in parentheses represent the standard deviations of the specimens. Different characters show significant differences $(p<0.05)$

$n$ number of specimens, $\sigma_{e p}$ stress at the proportional limit, $\sigma_{e 5 \%}$ stress at $5 \%$ strain of thickness ratio, $\sigma_{e 19 \%}$ stress at $19 \%$ strain of thickness ratio

\section{Tests of partial compression perpendicular to grain}

The experimental procedures of the tests of partial compression perpendicular to the grain followed JIS Z 2101 (Japanese industrial standard) [17]. The loading directions of the specimens without pith for objective (1) were the radial and tangential directions, as shown in Experiment I in Fig. 1. The loading direction of specimens without pith for objective (2) was the radial direction, as shown in Experiment II in Fig. 1. Universal testing machines with 10-ton and 2-ton capacities were used to apply loads to the specimens to meet objectives (1) and (2), respectively. The loading speed was kept under $0.98 \mathrm{MPa}$ per minute. The displacements of the loading to specimens for objectives (1) and (2) were measured using the crosshead movement of the testing machine and a displacement transducer with a $50-\mathrm{mm}$ range, respectively. The $\sigma_{\text {e }}$ for objectives (1) and (2) were calculated from the load divided by the specimens' width and the length of the loading plate $(40 \mathrm{~mm}$ or $20 \mathrm{~mm}$ ). For objective (1), the $\sigma_{\mathrm{e}}$ at a $5 \%$ strain of the thickness ratio $\left(\sigma_{\mathrm{e} 5 \%}\right)$ and the $\sigma_{\mathrm{e}}$ at a $19 \%$ strain of the thickness ratio $\left(\sigma_{\mathrm{e} 19 \%}\right)$ were obtained. The $\sigma_{\mathrm{e}}$ of structural timber was represented by the stress at a $20-\mathrm{mm}$ strain [18]. The 20-mm strain in boxed timber (105-mm thickness) was $19 \%$ strain of the thickness ratio. Therefore, we also examined $\sigma_{\mathrm{e} 19 \%}$ for objective (1). 
Observation of crushed tracheids near the loading surface of specimens

To gain a better understanding of the variation of $\sigma_{\mathrm{e}}$ among specimens for objective (1), crushed tracheids near the loading surface of specimens were observed using a SEM (scanning electron microscope) (Hitachi, S-3000N). After-tests of partial compression perpendicular to the grain, samples for SEM observation were cut from the loading surface of the specimens. Control samples were also cut from the unloading surface of the same specimens. Two specimens of each type (specimens without pith in tangential loading, specimens without pith under radial loading and specimens with pith) were observed.

\section{Measurements of density, MFA, latewood tracheid length and CE}

To meet objectives (1) and (2), the density $\left(\mathrm{g} / \mathrm{cm}^{3}\right)$ of all of the specimens was calculated from the weight and dimensions of air-dried specimens before loading. To meet objective (2), the MFA, latewood tracheid length and $\mathrm{CE}$ of the ring positioned at the center of the specimen for partial compression tests were examined. Fortynine specimens (from height positions of $1.5 \mathrm{~m}$ and $5.0 \mathrm{~m}$, one side of the radial direction from pith to bark) were selected for MFA, latewood tracheid length and CE measurements. The MFA values of earlywood and latewood were measured by the iodine-staining method [19]. $\mathrm{I}_{2}$ crystallized in the gaps between microfibrils in tangential sections of each ring, and the sections were observed with a light microscope. Under light microscopy, MFA was measured using image analysis software (Image J [20]). The MFA values of earlywood and latewood were obtained by averaging the measurements of 30 tracheids. For the tracheid length measurements, small specimens from the latewood of each ring were macerated. The tracheid length was measured under magnification $(50 \times)$, and the latewood tracheid length values were obtained by averaging the measurements of 50 tracheids. For $\mathrm{CE}$ measurements, cross sections of small specimens of each ring were smoothed using a sliding microtome. The microscopic digital images of the cross-sections were obtained under magnification $(700 \times)$ using a SEM. The $\mathrm{CE}$ of each ring, as shown in Fig. 2, was measured using image analysis software (Image J [20]). The accuracy of the measurement was $0.15 \mu \mathrm{m} / \mathrm{pixel}$, and the CE of each ring were obtained by averaging the measurements of 50 typical earlywood tracheids. In previous studies in which mechanical properties were calculated using cell models $[7,8]$, the lengths of the tangential and radial cell walls were measured as the CE. However, to simplify the measurement, we measured the tangential and radial diameters of lumens in the current study as shown in Fig. 2.

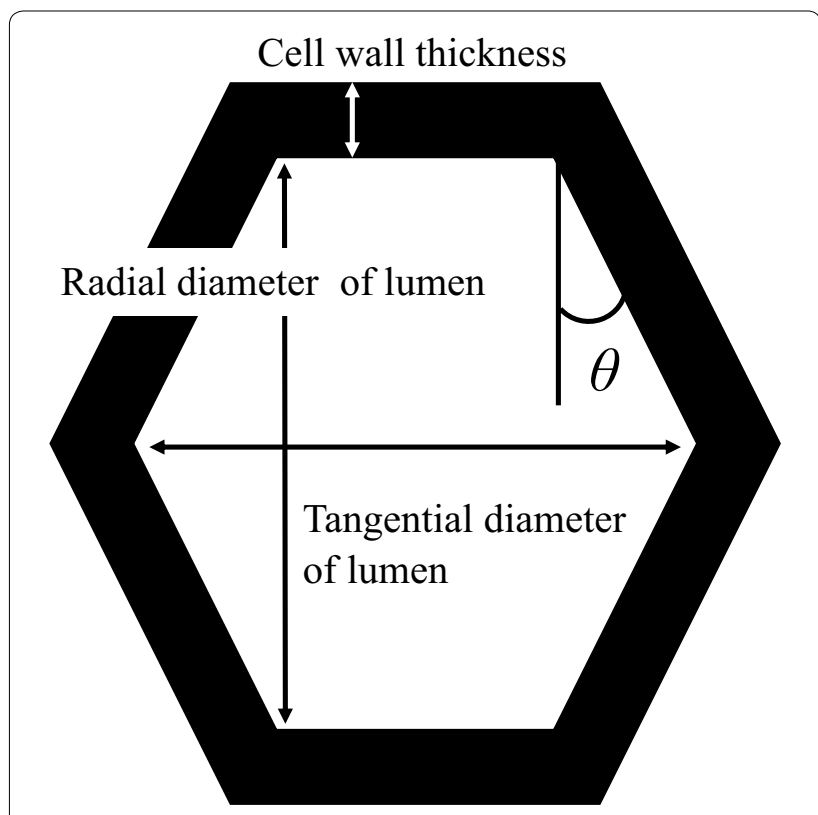

Fig. 2 Cross-sectional parameters of earlywood tracheids

\section{Statistical analysis}

For statistical analysis of the obtained data, statistical analysis software (SPSS ver. 16 with Regression and Advanced Models) was used. Using one-way ANOVA (analysis of variance) and multiple comparisons tests (Tukey's HSD test and the Bonferroni test), the significant differences in $\sigma_{\mathrm{e}}$ and in density among the types of specimens for objective (1) and the significant differences in $C E$ among the ring numbers for objective (2) were examined. By multiple linear regression analysis, a predictor equation for the $\sigma_{\mathrm{e} 5 \%}$ of sugi wood under loading in the radial direction was determined.

\section{Results}

Effects of loading direction on partial compression strength perpendicular to the grain

As shown in Table 1, there were no significant differences in $\sigma_{\mathrm{e} 5 \%}$ and $\sigma_{\mathrm{e} 19 \%}$ between the tangential and radial loading directions (multiple comparisons tests, $p>0.05$ ). Specimens without pith were separated into two groups based on radial position (Fig. 1 Experiment 1). However, there was no effect of radial position on $\sigma_{\mathrm{e} 5 \%}$ and $\sigma_{\mathrm{e} 19 \%}$ of specimens without pith. Therefore, these two groups were combined in Table 1. Specimens with pith had significantly larger $\sigma_{\mathrm{e} 5 \%}$ and $\sigma_{\mathrm{e} 19 \%}$ values than specimens without pith (multiple comparisons tests, $p<0.01$ ). It was recognized that the difference in the loading direction did not affect the difference of $\sigma_{\mathrm{e}}$ of sugi boards without pith. Specimens with pith had significantly larger density than specimens without pith (multiple comparisons tests, 
$p<0.05)$. Taken together, all the data in Table 1 show that there were significant positive correlations between density and $\sigma_{\mathrm{e}}\left(\sigma_{\mathrm{e} 5 \%}: r=0.74, \sigma_{\mathrm{e} 19 \%}: r=0.92, p<0.01\right)$.

\section{Observation of crushed tracheids near the loading surface of specimens}

Loading to the specimens for objective (1) was ended at a $25 \%$ strain-to-thickness ratio. Earlywood tracheids with relatively large cell lumens were crushed, although latewood tracheids and earlywood tracheids with relatively small cell lumens were not crushed in the specimen without pith under loading in the radial direction (Fig. 3a) or in the specimen with pith (Fig. 3c). As shown in Fig. 3c, earlywood tracheids in the specimen with pith were crushed in oblique direction. Under loading in the tangential direction, latewood buckled, and the boundary between earlywood and latewood was broken in the specimen without pith (Fig. 3b). Something like extractives blew off from the cell lumen of latewood in the specimen under loading in the tangential direction.

\section{Effects of density, MFA, latewood tracheid length, and CE on $\sigma_{\mathrm{e} 5 \%}$ under loading in the radial direction}

In the previous section, it was demonstrated that loading direction did not have an effect on $\sigma_{\mathrm{e}}$ of sugi wood.
Therefore, we focused on the effects of density, MFA, latewood tracheid length and $\mathrm{CE}$ on $\sigma_{\mathrm{e} 5 \%}$ under loading in the radial direction. As shown in Fig. 4, specimens with $\sigma_{\mathrm{e} 5 \%}>8 \mathrm{MPa}$ were from ring numbers $1-5$ except for one

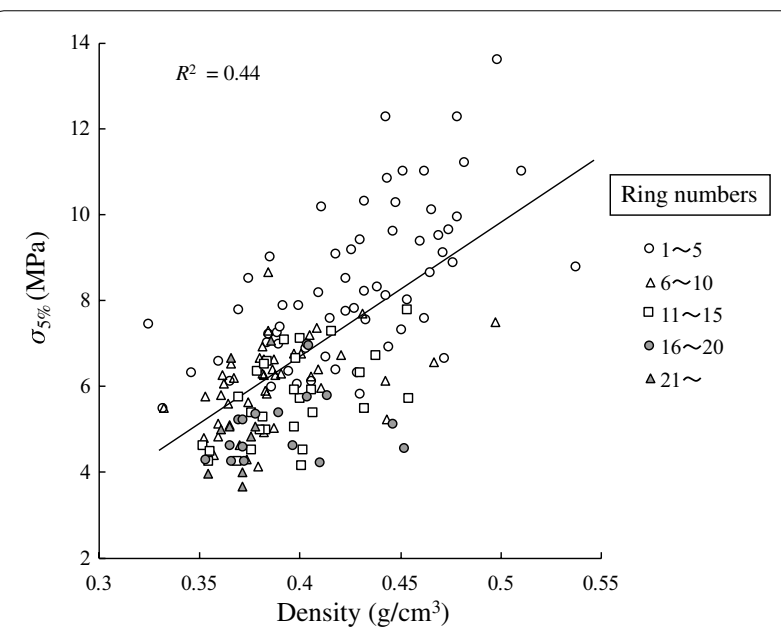

Fig. 4 Partial compression strength perpendicular to the grain of specimens from seven sugi cultivars. All specimens were loaded in the radial direction. Specimens were classified into five groups based on the ring number from the pith

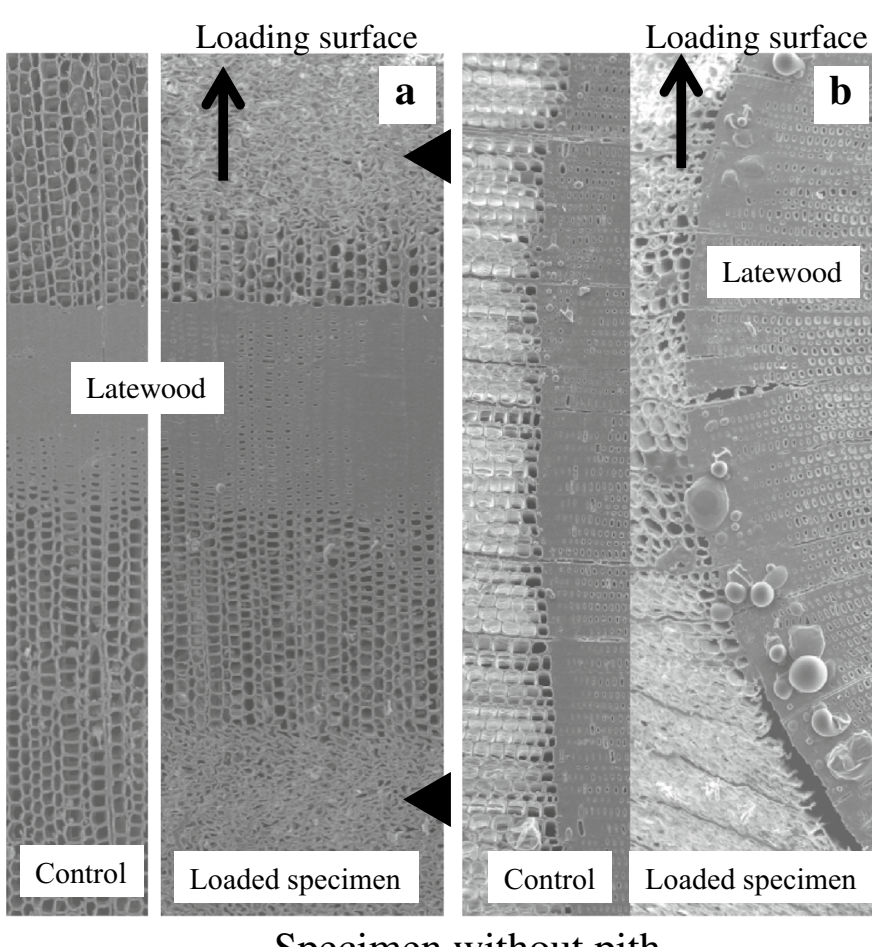

Specimen without pith

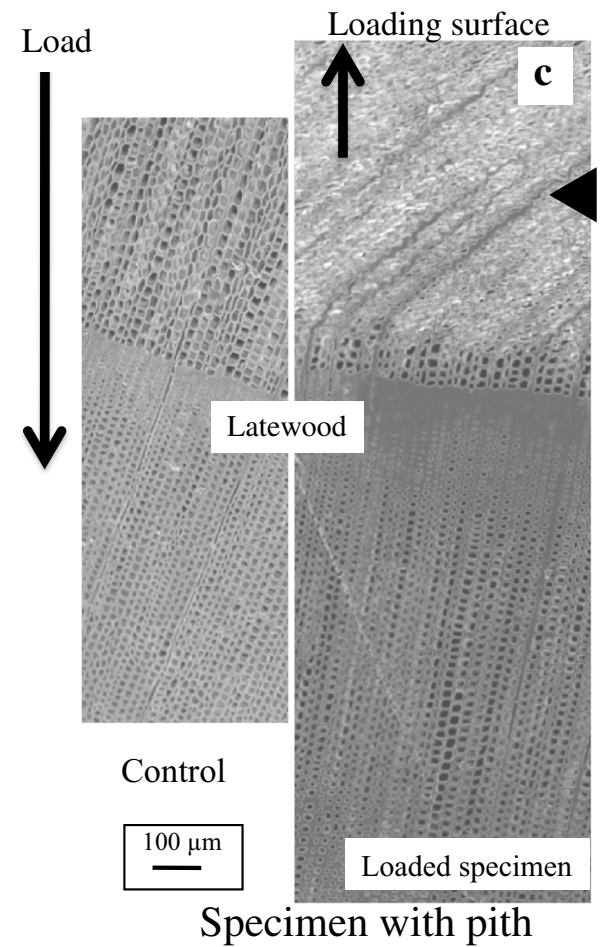

Specimen with pith

Fig. 3 a Shows specimen without pith under loading in radial direction. b Shows specimen without pith under loading in tangential direction. $\mathbf{c}$ Shows specimen with pith. Each picture includes control (left, specimen before loading) and loaded specimen (right) and shows the position of latewood. Short arrows show the position of loading surface and long arrow shows load direction. Scale bar $=100 \mu \mathrm{m}$ 
specimen from ring numbers $6-10$. There was a close correlation between density and $\sigma_{\mathrm{e} 5 \%}(r=0.66)$. However, the correlation between density and $\sigma_{\mathrm{e} 5 \%}$ in specimens from ring numbers $1-5$ was different from that in other specimens. The specimens with densities around $0.45 \mathrm{~g} / \mathrm{cm}^{3}$ showed large variation of $\sigma_{\mathrm{e} 5 \%}$. As shown in Table 2, CE significantly varied among the ring numbers. Earlywood tracheids in rings near the pith (ring numbers 1-5) had significantly smaller cross-sectional dimensions with a squarer shape (smaller $\theta$ in Fig. 2), larger $R / T$ and smaller cell wall thickness in comparison with those in the outer rings (ring numbers $6-10,11-15$ and 16-). These results were consistent with previous study [21]. As shown in Table 2, the smaller cross-sectional dimensions with square-shaped earlywood tracheids significantly increased $\sigma_{\mathrm{e} 5 \%}$. Although the effect of radial diameter/tangential diameter $(R / T)$ and cell wall thickness on $\sigma_{\mathrm{e} 5 \%}$ was significant, the effects were relatively small.
As shown in Fig. 5, it was demonstrated that there was a close positive correlation between the MFA of latewood and the $\sigma_{\mathrm{e} 5 \%}(r=0.84)$. The MFA of earlywood and the $\sigma_{\mathrm{e} 5 \%}$ also showed a close positive correlation $(r=0.81$, data not shown). Especially, specimens from ring number 1-5 had larger MFA and larger $\sigma_{\mathrm{e} 5 \%}$ in comparison with other specimens. Although there was a close correlation between density and $\sigma_{\mathrm{e} 5 \%}(r=0.73)$, more linear plots of MFA and $\sigma_{\mathrm{e} 5 \%}$ than of the density and $\sigma_{\mathrm{e} 5 \%}$ were obtained (Fig. 5). In addition, there was a negative correlation between the latewood tracheid length and the $\sigma_{\mathrm{e} 5 \%}(r=0.70$, data not shown). By multiple linear regression analysis, the predictor equation was determined to be as follows:

$$
\begin{aligned}
\sigma_{\mathrm{e} 5 \%}(\mathrm{MPa})= & 0.261 \times \operatorname{MFA}\left({ }^{\circ}\right)+15.526 \\
& \times \text { density }\left(\mathrm{g} / \mathrm{cm}^{3}\right)-4.432
\end{aligned}
$$

Table 2 Radial variation of cross-sectional parameters of earlywood tracheids and correlation coefficients between CE

\begin{tabular}{|c|c|c|c|c|c|}
\hline & \multicolumn{4}{|c|}{ Ring numbers } & \multirow{2}{*}{$\begin{array}{l}\text { Correlation } \\
\text { coefficients }\end{array}$} \\
\hline & $1-5$ & $6-10$ & $11-15$ & $16-$ & \\
\hline Tangential diameter $(\mu \mathrm{m})$ & $18.3(4.3)^{\mathrm{a}}$ & $22.4(5.1)^{b}$ & $25.1(4.8)^{c}$ & $25.6(5.0)^{c}$ & $-0.560^{* *}$ \\
\hline Radial diameter ( $\mu \mathrm{m})$ & $29.9(6.6)^{\mathrm{a}}$ & $34.4(7.0)^{b}$ & $38.2(6.6)^{c}$ & $36.8(7.8)^{d}$ & $-0.447^{* *}$ \\
\hline$R / T$ & $1.7(0.5)^{\mathrm{a}}$ & $1.6(0.4)^{b}$ & $1.56(0.4)^{b}$ & $1.48(0.4)^{c}$ & $0.303^{*}$ \\
\hline Cell wall thickness $(\mu \mathrm{m})$ & $1.3(0.3)^{\mathrm{a}}$ & $1.4(0.3)^{b}$ & $1.5(0.3)^{c}$ & $1.5(0.3)^{c}$ & $-0.356^{*}$ \\
\hline$\theta\left(^{\circ}\right)$ & $9.2(7.3)^{\mathrm{a}}$ & $10.3(7.8)^{b}$ & $15.5(9.1)^{c}$ & $17.8(9.4)^{d}$ & $-0.425^{* *}$ \\
\hline$n$ & 740 & 1000 & 550 & 849 & 49 \\
\hline
\end{tabular}
and $\sigma_{\mathrm{e} 5 \%}$ of specimens from seven sugi cultivars

Forty-nine specimens were selected from the specimens shown in Fig. 4 for the measurement of cross-sectional parameters of earlywood tracheids. Cross-sectional parameters are shown in Fig. 2. The values represent averages for each range of ring numbers; values in parentheses indicate standard deviations

Different characters show significant differences among ring number zones $(p<0.01) . R / T$ radial diameter/tangential diameter, $n$ number of measured tracheids and number of samples which correlation coefficients were obtained from; ${ }^{*} p<0.05 ;{ }^{* *} p<0.01$
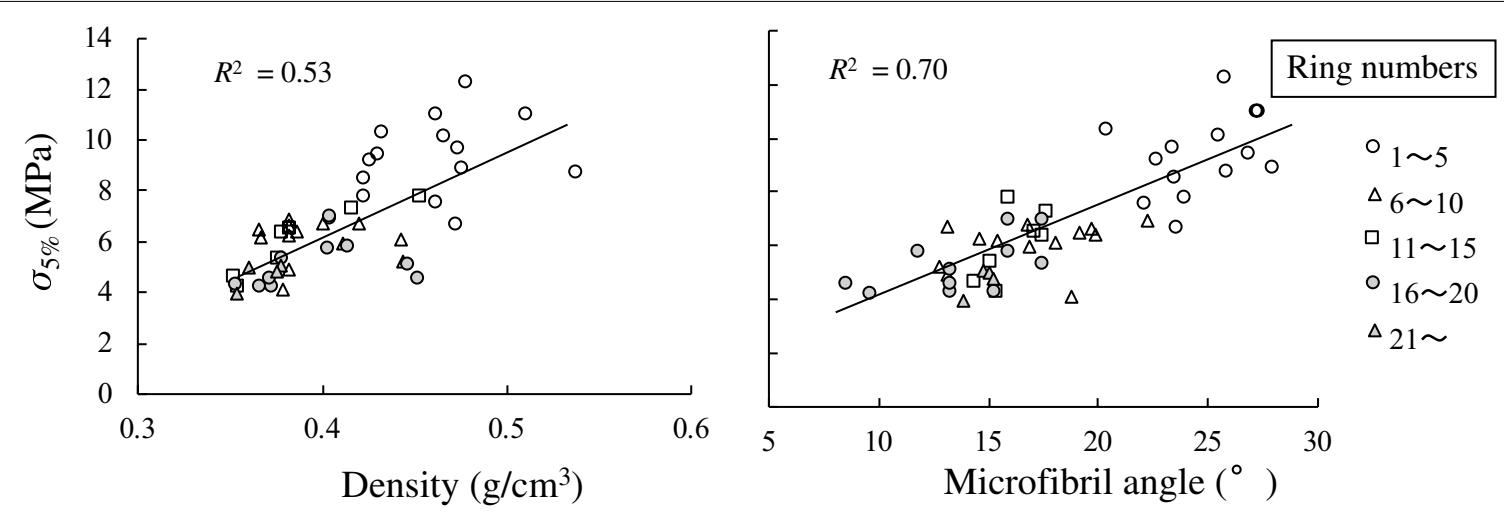

Fig. 5 Effects of density and MFA on $\sigma_{e 5 \%}$ in seven sugi cultivars. Forty-nine specimens were selected from the specimens shown in Fig. 4 for the measurement of the microfibril angle. All specimens were loaded in the radial direction. Specimens were classified into five groups based on the ring number from the pith 
This equation could help in the prediction and explanation of the variation of the $\sigma_{\mathrm{e} 5 \%}$ of sugi wood under loading in the radial direction (adjusted $R^{2}=0.75$ ). By stepwise linear regression, it was determined that $C E$ were not effective parameters for the predictor equation. We assumed that latewood tracheid length was not an effective parameter for the predictor equation. Because a close correlation between latewood tracheid length and MFA $(r=0.73)$ was recognized, and the effect of latewood tracheid length on the $\sigma_{\mathrm{e} 5 \%}$ was smaller than the effects of MFA and density. Based on the standardized partial regression coefficients (density: 0.335, MFA: $0.625)$, it was recognized that MFA had a larger effect on the $\sigma_{\mathrm{e} 5 \%}$ of sugi wood than did density.

\section{Discussion}

In the current study, there were no significant differences in $\sigma_{\mathrm{e} 5 \%}$ and $\sigma_{\mathrm{e} 19 \%}$ between specimens under loading in the tangential and radial directions (Table 1). The results obtained in this study were also seen in Norway spruce (Picea abies) [22] and hinoki (C. obtusa) [23]. In contrast, $\sigma_{\text {e5\% }}$ under loading in the tangential direction was larger than that under loading in the radial direction in four coniferous tree species [5]. As the reason for the larger $\sigma_{\mathrm{e} 5 \%}$ under loading in the tangential direction, it was considered that vertically lined latewood protected the weak earlywood from being crushed [5]. In the Japanese larch (Larix kaempferi), the $\sigma_{\mathrm{e}}$ with loading in the tangential direction increased with density; however, the $\sigma_{\mathrm{e}}$ with loading in the radial direction did not correlate with density [24]. In Picea spp. and Chamaecyparis spp., latewood is not pronounced, and the transition from earlywood to latewood is usually gradual [25]. Sugi has relatively narrow latewood, and the percentage of latewood decreases with ring width [26]. As shown in Fig. 3b, the latewood of sugi specimens without pith was buckling due to loading in the tangential direction. Because of the relatively narrow latewood in these species, vertically lined narrow latewood might break easily due to compression buckling under loading in the tangential direction. The absence of a significant difference in $\sigma_{\mathrm{e} 5 \%}$ and $\sigma_{\mathrm{e} 19 \%}$ between sugi specimens without pith under loading in the radial and tangential directions might be due to the relatively narrow latewood of specimens without pith. In this study, however, effects of loading direction on $\sigma_{\mathrm{e}}$ in specimens with pith remained unclear.

As shown in Table 1 and Fig. 4, specimens with pith and specimens containing ring numbers $1-5$ had significantly larger $\sigma_{\mathrm{e} 5 \%}$ values than specimens without pith and specimens with outer rings, respectively. Our results obtained in sugi are consistent with previous results obtained in sugi [3] and Norway spruce [27]; however, results contrary to our results were obtained in Japanese larch [24] and loblolly pine [28]. Wood densities in Japanese larch and most hard pines were low values near the tree center with an increase toward the bark [24, 29]. In contrast, the density of sugi and Norway spruce showed high values at the tree center, dropping through the juvenile wood zone, and then rising slightly in a radial pattern $[4,30]$. As previously described, there was a significant positive correlation between density and $\sigma_{\mathrm{e}}$. Therefore, superior $\sigma_{\mathrm{e} 5 \%}$ values near the pith might be observed in a part of tree species with larger density at the tree center.

In the current study, MFA had a closer correlation with the $\sigma_{\mathrm{e} 5 \%}$ of sugi wood under loading in the radial direction than did other parameters. A larger MFA might increase the mechanical properties perpendicular to the grain, because the microfibrils with larger MFAs were arranged more parallel to the direction of loading and resist the stress efficiently than did those with smaller MFAs.

Gibson and Ashby pointed out that $\rho / \rho s$ ( $\rho$ : density of cellular materials; $\rho$ s: density of cell wall) was an important parameter in the mechanism through which the mechanical properties of cellular materials function [31]. Cellular structures have been found to be important parameters affecting the mechanical properties of cellular materials with $\rho / \rho s \leqq 0.3$, although the cell wall characteristics were found to be important parameters affecting the mechanical properties of cellular materials with $\rho / \rho s>0.3$ [32]. Based on these assumptions, Watanabe showed that mechanical properties perpendicular to the grain of wood with density $\leqq 0.44 \mathrm{~g} / \mathrm{cm}^{3}$ significantly depended on the cellular structures [32]. As shown in Table 1 and Fig. 4, the average densities of the specimens with pith and specimens containing ring numbers $1-5$ were $0.49 \mathrm{~g} / \mathrm{cm}^{3}$ and $0.46 \mathrm{~g} / \mathrm{cm}^{3}$, respectively. Although the density of earlywood mainly crushed by the compression assumed to be smaller than average densities, the densities of earlywoods near the pith were expected to be larger than those of outer wood because of the smaller cross-sectional dimensions with a square shape in earlywood tracheids near the pith (Table 2). Saiki also pointed out that cell wall ratio in earlywood near the pith was larger than that of outer wood [21]. Therefore, cell wall characteristics (MFA) might be more effective than cellular structures (CE) in determining the variation of $\sigma_{\mathrm{e} 5 \%}$ near the pith.

As previously described, the mechanical properties perpendicular to the grain of wood with density $\leqq 0.44 \mathrm{~g} /$ $\mathrm{cm}^{3}$ significantly depended on the cellular structures [32]. Based on this assumption, we classified forty-nine specimens into two groups; specimens with density $<0.44 \mathrm{~g} /$ $\mathrm{cm}^{3}$ and specimens with density $>0.44 \mathrm{~g} / \mathrm{cm}^{3}$ and examined the effective parameters on $\sigma_{\mathrm{e} 5 \%}$ in each group. Although effective parameters for $\sigma_{\mathrm{e} 5 \%}$ in specimens with density $<0.44 \mathrm{~g} / \mathrm{cm}^{3}$ were density and MFA $(r=0.82$, 
0.75 , respectively, $n=35$ ), effective parameters for $\sigma_{\mathrm{e} 5 \%}$ in specimens with density $>0.44 \mathrm{~g} / \mathrm{cm}^{3}$ were MFA and $\theta$ in Fig. $2(r=0.85,0.71$, respectively, $n=14)$. However, we assumed that $\theta$ was not an effective parameter, because a close correlation between $\theta$ and MFA $(r=0.76)$ was recognized, and the effect of $\theta$ on the $\sigma_{\mathrm{e} 5 \%}$ was smaller than the effects of MFA. The effect of MFA on $\sigma_{\mathrm{e} 5 \%}$ increased in specimens with larger density. However, it would be premature to conclude that the superior $\sigma_{\mathrm{e}}$ of sugi boards with pith was mainly induced by large MFA near the pith. There were large variations of the parameters (wood density, MFA and CE) affecting $\sigma_{\mathrm{e} 5 \%}$ from wood near the pith to outer wood in this study. Both density and MFA of the sugi wood near the pith are larger than those of the outer wood. Therefore, based only on sugi data, it might be difficult to evaluate the effect of MFA on $\sigma_{\text {e5\% }}$ separately from the effects of density. The specimens near the pith in Japanese larch and loblolly pine did not have superior $\sigma_{\mathrm{e}}$ [24, 28], although larger MFAs near the pith were expected. To evaluate the effect of MFA on $\sigma_{\mathrm{e} 5 \%}$ more accurately, we should examine the effects of MFA on $\sigma_{\mathrm{e} 5 \%}$ in the species with different wood properties from sugi wood. In the future study, we will examine hinoki and pine trees, and evaluate the effects of MFA on $\sigma_{\mathrm{e} 5 \%}$ near the pith based on the obtained all results.

\section{Conclusions}

Although it was widely recognized that smaller MFAs in the $\mathrm{S}_{2}$ layer of tracheids increased the mechanical properties of many plantation tree species parallel to the grain, the effects of MFA on mechanical properties perpendicular to the grain still remain unclear. In this study, we demonstrated that a larger MFA increased the $\sigma_{\mathrm{e} 5 \%}$ in sugi wood for the first time. This positive correlation assumed to be very important for efficient use of sugi wood near the pith, although we need more studies on the species with different wood properties from sugi wood to evaluate the effect of MFA on $\sigma_{\mathrm{e} 5 \%}$ more accurately. The future studies focused on the positive effect of larger MFA on $\sigma_{\mathrm{e}}$ might contribute to developing wood products with superior $\sigma_{\mathrm{e}}$ and appropriate use of wood with poor mechanical properties in longitudinal direction.

\section{Abbreviations}

$\sigma_{\mathrm{e}}$ : partial compression strength perpendicular to the grain; $\sigma_{\mathrm{e} 5 \%}$ : the $\sigma_{\mathrm{e}}$ at a $5 \%$ strain of the thickness ratio; $\sigma_{e 10 \%}$ : the $\sigma_{e}$ at a $19 \%$ strain of the thickness ratio; MFA: microfibril angle; CE: cross-sectional parameters of earlywood tracheids; JIS: Japanese industrial standard; SEM: scanning electron microscope; p: density of cellular materials; ps: density of cell wall.
\end{abstract}

\section{Authors' contributions}

YK designed this study and examined mechanical and anatomical properties of sugi wood, and was a major contributor in writing the manuscript. HM, SA and TA contribute to experimental method and build the hypothesis in this study. TT contributes to discussion on the obtained results. All authors read and approved the final manuscript.

\section{Author details}

${ }^{1}$ Division of Forest and Environmental Science, Faculty of Agriculture, University of Miyazaki, Miyazaki 889-2192, Japan. ${ }^{2}$ Miyazaki Prefectural Wood Utilization Research Center, Miyazaki 885-0037, Japan.

\section{Acknowledgements}

The authors would like to thank Mr. Takuma Karitani, Ms. Minami Sumita and Mr. Tatsuya Nagaishi for contribution to data collection.

\section{Competing interests}

The authors declare that they have no competing interests.

Availability of data and materials

Not applicable.

Funding

No funding was received.

\section{Publisher's Note}

Springer Nature remains neutral with regard to jurisdictional claims in published maps and institutional affiliations.

Received: 31 October 2018 Accepted: 6 March 2019

Published online: 19 March 2019

\section{References}

1. Zobel BJ, Sprague JR (1998) Juvenile wood in forest trees. Springer, Berlin, pp 1-3

2. Tian X, Cown DJ, Lausberg MJ (1995) Modeling of Pinus radiata wood properties. Part I. Spiral grain. N Z J For Sci 25:200-213

3. Morita H, Aratake S (2010) Development of laminated wood for sill plates using Obi-sugi (Cryptmeria japonica) with pith. J Timber Eng 23:137-143 (in Japanese)

4. Ohta S, Watanabe H, Matsumoto T, Tsutsumi J (1968) Studies on mechanical properties of juvenile wood I. Fibril angle and dynamic modulus of elasticity of juvenile wood in the stem of sugi trees (Cryptmeria japonica). Rep Kyusyu Univ For 22:105-116 (in Japanese)

5. Ido H, Nagao H, Kato H, Miyatake A, Hiramatsu Y (2010) Strength peoperties of laminated venner lumber in compression perpendicular to its grain. J Wood Sci 56:422-428

6. Ando K, Onda H (1999) Mechanism for deformation of wood as a honeycomb structure I: effect of anatomy on the initial deformation process during radial compression. J Wood Sci 45:120-126

7. Ando K, Onda H (1999) Mechanism for deformation of wood as a honeycomb structure II: first buckling mechanism of cell walls under radial compression using the generalized cell model. J Wood Sci 45:250-253

8. Watanabe U, Norimoto M, Ohgama T, Fujita M (1999) Tangential Young's modulus of coniferous early wood investigated using cell models. Holzforschung 53:209-214

9. Yang JL, Evans R (2003) Prediction of MOE of eucalypt wood from microfibril angle and density. Holz Roh Werkstoff 61:449-452

10. Lachenbruch B, Johnson GR, Downes GM, Evans R (2010) Relationships of density, microfibril angle, and sound velocity with stiffness and strength in mature wood of Douglas-fir. Can J For Res 40:55-64

11. Mclean JP, Evans R, Moore JR (2010) Predicting the longitudinal modulus of elasticity of Sitka spruce from cellulose orientation and abundance. Holzforschung 64:495-500

12. Kijidani Y, Kitahara R (2009) Variation of wood properties with height position in the stem s of Obi-sugi cultivars. Mokuzai Gakkaishi 55:198-206 (in Japanese)

13. Kijidani Y, Kitahara R (2005) Effects of basic wood properties on strength and stiffness in bending of Cryptomeria japonica timbers. J Soc Mat Sci Japan 54:377-380 (in Japanese)

14. Kijidani Y, Kawasaki Y, Matsuda D, Nakazono F, Hayakawa M, Mutaguchi H, Sakagami H (2014) Tree heights in the ring-formed years affect microfibril 
angles in the rings from juvenile to mature wood at breast height in hinoki trees (Chamaecyparis obtusa). J Wood Sci 60:381-388

15. Kijidani Y, Kitahara R, Sasaki Y, Onoda M (2001) Wood Properties of Cryptomeria Japonica in Southern Kyushu I factors affecting strength of Yakushima-Sugi woods. J Soc Mater Sci Jpn 50:391-396 (in Japanese)

16. Sobue N, Asano I (1976) Studies on the fine structure and mechanical properties of wood on the longitudinal Young's modulus and shear modulus of rigidity of cell wall. Mokuzai Gakkaishi 22:211-216 (in Japanese)

17. Japanese Industrial Standard (2009) Methods of testing for woods. Japanese Industrial Association, Tokyo, pp 21-22 (in Japanese)

18. Japan Housing and Wood Technology Center (2011) The strength test manual of structure timber material. Japan Housing and Wood Technology Center, Tokyo (in Japanese)

19. Saiki H, Xu Y, Fujita M (1989) The fibrillar orientation and microscopic measurement of the fibril angles in young tracheid walls of sugi (Cryptomeria japonica). Mokuzai Gakkaishi 35:786-792 (in Japanese)

20. Abramoff MD, Magalhaes PJ, Ram SJ (2004) Image processing with ImageJ. Biophotonics Int 11:36-42

21. Saiki H (1965) Studies on the annual ring structure of coniferous wood. V. Variation from the pith toward the outside. Mokuzai Gakkaishi 11:185-190 (in Japanese)

22. Hoffmeyer P, Damkilde L, Pedersen TN (2000) Structural timber and glulam in compression perpendicular to grain. Holz als Roh- und Werkstoff 58:73-80

23. Ido H, Nagao H, Kato H (2012) Strength properties of Japanese cypress (Chamaecyparis obtusa) pithless lumber and small clear specimens sawn from a large diameter log. Bull For For Prod Res Inst 424:121-133 (in Japanese)
24. Ishikura Y, Matsumoto K, Ohashi Y (2012) Radial variation in partial compression properties perpendicular to the grain of Japanese larch (Larix kaempferi). J Wood Sci 58:399-407

25. Panshin AJ, de Zeeuw C (1980) Textbook of wood technology. McGrawHill, New York, pp 457-492

26. Fujiwara S (1995) Changes in tracheid dimension and ring structure related to ring width in sugi (Cryptomeria japonica) and hinoki (Chamaecyparis obtusa). Mokuzai Gakkaishi 41:774-779 (in Japanese)

27. Rosner Sabine, Karlsson Bo (2011) Hydraulic efficiency compromises compression strength perpenducular to the grain in Norway spruce trunkwood. Trees 25:289-299

28. Kretschmann DE (2008) Influence of juvenile wood content on shear parallel, compression, and tension perpendicular to grain strength and mode I fracture toughness for loblolly pine at various ring orientation. For Prod J 58:89-96

29. Zobel BJ, Sprague JR (1998) Juvenile wood in forest trees. Springer, Berlin, p p11

30. Kuccera B (1994) A hypothesis relating current annual height increment to juvenile wood formation in Norway spruce. Wood Fiber Sci 26:152-167

31. Gibson LJ, Ashby MF (1988) Cellular solids structure \& properties. Pergamon press, Tokyo, p p3

32. Watanabe U (2011) Variation of cellular structure and transverse Young's modulus. In: Fukushima K, Funada R, Sugiyama J, Takabe K, Umezawa T, Yamamoto $\mathrm{H}$ (eds) Secondary xylem formation-introduction to biomass science, 2nd edn. Kaiseisha Press, Otsu, pp 497-498 (in Japanese)

\section{Submit your manuscript to a SpringerOpen ${ }^{\circ}$ journal and benefit from:}

- Convenient online submission

$\checkmark$ Rigorous peer review

- Open access: articles freely available online

- High visibility within the field

- Retaining the copyright to your article

Submit your next manuscript at $\mathbf{s p r i n g e r o p e n . c o m ~}$ 